\title{
INSTRUÇĀO PROGRAMADA
}

\author{
Moema Guedes Barbato*
}

\section{1 - INTRODUÇÃo}

A Instrução Programada (I. P.), é mais um méto do pedagógico entre os muitos que conhecemos da escola reno vadora. Caracteriza-se pela auto-instrução e consequlentemen te pela intensa atividade intelectual do educando. A diferença fundamental entre êste método e 08 demais é justamente a con corrência efetiva de uma equipe de profissionais especializados e competentes que juntos traçam, eleboram, testam e organi zam os vários programas. São êles:

- o paicólogo, colaborando intensivamente, verifica se no conteúdo do texto há estímulo necessário para que o educań do sinta entusinsmo em prosseguir nos seus estudos e se há quantidade exata de reforços exigidos na aprendizagem;

- o pedagogo concorre com a sua capacidade para verifi car a técnica empregada, a terminologia própria, a sequência lógica;

- o especialista na matéria traça o conteudo do progra ma e com os conhecimentos profundos da mesma êle pode dosar, exatamente, 'o que achn mais necessário que os determina dos grupos de alunos aprendam.

A reuniāo dêsses trếs elementos, altamente espe cializados, torna possível a realizaçāo do método.

2-HISTORICO E FUNDAMENTAÇÃO CIENTIFICA DOMETODO

Em 1913, John B.Watson iniciou seus estudos sobre teorias paicológicas do comportamento e realizou as primeiras

* Inatrutora de Pedagogia e Didática aplicada à Enfermagem, da Escola de Enfermagem da USP. 
investigaçōes sôbre a teoria do estímulo-resposta. Posterior mente foram confirmadas cientificamente, por Karl Lachley, cu jas experiências em animais vieram esclarecer a importância do córtex cerebral no processo da aprendizagem.

Ano após ano, as experiências realizadas foram se somando até que, em 1920, Sidney Pressey idealizou a pri meira máquina de ensinar, baseando-se em que o comportamen to gratificado tem maior probabilidade de repetir-se. Assim é que, as líçōes calocadas naquela máquina, já ofereciam 20 a luno essas con diçōes e serviam para avaliá-lo atrevés de per guntas e respostas múltiplas. Bvidentemente, Pressey adian tou-se em 25 anos à sus época. Os educadores de entāo nāo se mostraram inuito interessados pelo nôvo método pedagógico que surgia. Em 1954, Skinner, da Universidade de Harvard, efetuou estudos mais profundos sôbre a técnica do comportamento, salientando a importância do refốço no processo da aprendiza gem: estímulo - resposta - refôrço - retôrno de conhecimentos.

ESTIMULO - O aluno deve se sentir estimulado diante de um programa. Isso se consegue, em parte, quando se entrega ao mesmo, no início do curso a ser ministrado, os objetivos do programa cuidadosamente traçados emitêrmos do comportamen to final desejado. Também na instruçāo programada a equipe descreve $O$ texto continuando a sentença de maneiraque 0 aluno seja estimulado, através de um raciocínio lógico e fácil, a che gar ao final de cada período (quadros, em linguagem de I.P.) com a resposta pràticamente sabida.

RESPOSTA - REFORÇO - Quando, no final de cada quadro, o aluno responde à pergunta formulada e verifica que sua respos ta é correta, âle está recebendo um prémio e consequientemen te hí um refôrço dos conhecimentos adquiridos. A pessoa, . freate a um programa idealizado nos moldes da I. P.. sente-se estimulada de tal maneira que o termina com uma rapidez im pressionante já esperada pelos programadores.

Caberia cttar aqui. Don H. Parker: (*) "t de dese

(*) Postllas fornecidas pela Organizagão Mundial de saúde nô bre Instrugão Programada, impressa no Médico. 
jar-se que se proporcione uma situaçāo escolar tal, que cada aluno possa iniciar sua aprendizagem levando-se em conta 0 que êle já conhece e avançar tão ràpidam ente e tão longe, quan to sua capacidade de aprendizagem lhe permita". Isto é em re sumo o método de I. $P$.

3 - ESTRUTURA BASICA DA INSTRUÇĀO PROGRAMADA

Existem dois típos de apresentação do método de I. P. : linear ou da construçāo da resposta e intrínseco ou da se leçäo de resposta.

1. No método linear, também conhecido pelo nome de "Skinner", a matéria é apresentada em pequenos quadros con tendo apenas uma idéia de cada vez. Características:

a) quadros com poucas oraçōes contendo aproximadamen te 25 ou 30 palarras; apenas uma informaçāo por vez.

b) linguagem fácil, concisa e clara;

c) resposta induzida no final de cada quadro;

d) matéria apresentada pouco a pouco, partindo do mais simples para o mais complexo, do conhecimento para o desco nhecido, do concreto para o abstrato;

e) confirmação imediata, dentro de cada quadro.

2. No método intrínseco, também chamado de "Crowder" o número de informaçōes contidas em cada quadro é maior,com mais de uma resposta para que o aluno selecione a que acha correta. Características:

a) períodos maiores contendo várias informaçōes, poden do ser encontradas 3 ou 4 sentenças e até mesmo conteúdo que ocupe tôda uma págiña:

b) linguagem fácil e clara;

c) respostas múltiplas; seleçāo de uma resposta entre três apresentadas;

d) matéria dada de maneira completa em cada quadro a bordando 08 pontos essenciais;

e) confirmação imediata dada em outra página.

4 -PRINCÍPIOS QUE REGEM O METODO DA INSTRUÇÃO PRO GRAMADA

Sāo cinco os princíplos da I. P. 
19 - Princípio dos períodos fácels.

Deve ser uma constente na execução dos textos o uso da linguagem clara e ascessível para o aluno para o qual o programa se destina.

Uma vez elaborado o livro de texto, para determi nado grupo, qualquer individuo, enquadrado nessa classe, deve compreendê-lo, independente de sua capacidade de aprendizagem.

29 - Princípio das respostas freqilentes.

Na construçäo dos quadros o programador tem a preocupação de induzir o aluno a dar uma resposta correta no final do mesmo. Esta resposta é um estímulo constante para que o aluno se sinta motivado a dar prosseguimento so seu pro grama.

39 - Princípio da confirmação imediata.

Já vimos, na introdução dêste trabalho, que nāo a diantaria estimular o aluno sem premiá-lo. Esse prêmio, por tanto, the é apresentado quando êle varifica se a sua resposta está correta. Esta é encontrada dentro dos quadros, ou em ou tra página dependendo da técnica usada. Seus conhecimentos foram reforçados a êle se encontra altamente motívado a pros seguir com sua lição.

49 - Princípio do ritmo individual.

Cada indivíduo tem a sua própria capacidade de a prendizagem. Evidentemente que a classe, à qual estamos apli cando o método da I. P., deve ter uma capacidade média de a prendizagem. A preocupaçāo dêsse sistema é de respeitar a lí f̧ão de acôrdo com o seu grau de inteligência, sua capacidade em assimilar com maior ou menor rapidez o conteúdo da maté ria, sob condiçōes psicológicas normais.

59 - Princípio de elíminaçāo de êrros.

Êste princípio diz respeito exclusivamente ao pro fessor. Quando o mesmo, revendo seu programa, verifica que um determinado quadro fol respondido erradamente por mais ou menos $5 \%$ a $10 \%$ dos alunos, êle deve voltar tôda a sua aten gāo para o mesmo, tentando modificí-lo ou eliminando-o do tex to. Dal nasce a necesaldade da revisäo freqitlente dos programas. 
Citaremos algumas vantagens mais evidentes:

i. Eficiência comprovada do método.

A eficiência do método de I. P. é indiscutível. A prova contundente da eficácia dêste método é seu uso em larga escala nos Estados Unidos da América, quer nos melos escola res, quer na indústria onde sāo elaborados programas com a fi nalidade de preparar indivíduos, a curto prazo, para o manejo de aparelhos, máquinas, etc.

2. Tempo requerido, para aprendizagem.

O tempo que se dispende para se dar um determi nado programa pelos métodos tradicionais é reduzido pela meta de quando o fazemos pelo método de I. P. Esta nossa afirmati va já foi testada, em algumas universidades norte americanas.

3. Aprendizagem sem a presença física e constante do mestre.

Tratando-se de uma auto-instrução a presença do professor só se faz necessária em determinadas circunstâncias, isto $\dot{e}$, quando o aluno não entende certo quadro ou quando é so licitado a comparecer à presença do professor para uma parte prática ou para maiores esclarecimentos. Desta maneira o pro fessor disporá de grande parte de seu tempo para planejar outros programas ou qualquer outra atividade.

4. Respeito $\dot{a}$ individualidade do aluno.

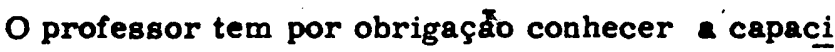
dade, o comportamento e as atitudes do seu aluno para que pos sa atuar com precisão sobre a personalidade do mesmo. Cada aluno é um indivíduo com características próprias, e como tal ele é observado e orientado.

5. Notivação constante.

A motivação do aluno é contínua; cada quadro con cluído acertadamente é um incentivo para que êle prossiga na leitura da matéria.

6. Número de alunos.

As classes podem ser nùmericamente grandes. Co mo os alunos estudam sòzinhos e têm sua própria capacidade de aprendizagem, lògicamente terminarão suas liçōes em tem pos diferentes, permitindo ao professor atendê-los quando ne cessário, com eflciéncin e sem perda de tempo. 
6 - CRITICAS AO METODO

As críticas em relação a método são poucas e a principal decorre do problema econômico de país em desenvol vimento. Vejamos quais são:

1. Problema econômico.

A I. P. é um método altamente custoso porquanto, para a realizaçāo dos programas, se necessita de uma verba substancial para: a) renumerar a equipe de profissionais de al to gabarito; b) saldar as despesas com os grandes gastos que se tem com material, principalmente papel, e a impressāo de livros de textos. Lembramos aqui que cada aluno necessita um exemplar de cada matéria programada.

2. Problema do individualismo.

O processode socializaçào dos grupos, que tanto interessa ao professor na metodologia moderna, de fazer com que os educandos aprendam a viver e trabalhar juntos, em equi pe, neste método nāo se verifica, pois 0 in indivíduos aprendem sòzinhos, consequentemente marginalizando-se do resto do gru po.

Säo estas as duas críticas que poderíamos fazer. Para minorar esta segunda desvantagem o professor pode tra car um plano onde haja outras oportunidades para solicializar 08 grupos.

\section{- 7 - APROVEITAM ENTO DO METODO DE I. P. NO ENSINO DA ENFERMAGEM}

O uso dêsse método no ensino da enfermagem é possível e até mesmo recomendável. Nos Estados Unidos êle nāo só foi aceito como um método de comprovada eficiência, co mo a sua adoçio por vírias escolas é uma realidade.

Alguns assuntos sôbre enfermagem escritos no mé todo de I.P. sāo de autores norte-americanos. Há poucos tra duçōes para o castelhano è raríssimas para o português.

Èste método seria uma arma importante para as escolas, no preparo rípido e eficiente do pessoal auxiliar e pa re os hospitais no desenvolvimento dos programas de educação em serviço, preparando pessoal atendentes de límpeza etc., para exiercerem suas exatas funçōes. 
Ainda através do emprêgo dêsse método poderín mos formar classes nùmericamente superiores às atuals e tam bém, como já vimos anteriormente, o tempo gasto em executar os programas seria reduzido. Estaríamos contribuindo, dessa maneira, para resolver o probleme angustioso da falta de pes soal profissional.

O curso de Graduação provìvelmente muito se be neficiaria se alguns dos seus programas fossem apresentados sob forma de I. P. Pouparímos esforços dos professores, os alunos estariam constatemente motivados e o cansaço que pro vém das frequtentes aulas tradicionais seria abolido.

O problema do número de pessoal nāo habilitado (atendentes) que trabal ha em enfermagem é tão grande na Amé ria Latina (calculados em 100.000 indivíduos)que a Organizaçāo Mundial de Saúde organizou cursos intensivos para enfermeiras latino-americanas, com a finalidade de ensinar-lhes 0 método de I.P. visando o preparo e promogão daquele pessoal a curto prazo. Désses cursos participaram 6 enfermeiras brasileiras.

A Escola de Enfermagem de Ribeirāo Prêto, da Universidade de São Paulo, vem se destacando entre as Escolas de Enfermagem do mesmo Estado como uma das pioneiras na tentativa do emprêgo do referido método.

Ainda na USP há um grupo de psicólogos da cadei ra de Psicologia Educacional da Faculdade de Fllosofia, Ciên cias e Letras, vem, nāo só organizando programas como for mando programadoras para atuarem na realização de futuros 1 i vros de texto, elaborados sob método de I.P.

Seria multo interessante que 08 poderes constituf dos contribuíssem com verbas, para que juntos, psicólogos e enfermeiras especializadas, pudéssem planejar programas pa ra 08 cursos de enfermagem, atendendo de imediato a forma ção rápida de pessoal de enfermagem de que tanto o Brasil ne cessita.

Para finalizar apresentamos em seguida, como e xemplo, alguns quadros (tipo Linear) de uma liçāo para auxilia res de Enfermagem.

Tôda aula programada trás instruçōes sobre como proceder durante a leitura da mesma. Exemplo:

"Esta lição contém a informação básica que se ne 
cessita para medir a temperatura. A prática se fará posterior mente no campo hospitalar.

18. - Estude cada quadro. Observe que hí nele um espe ço ou vários espaços em branco. Decida qual a palavra ou paie vras corretas e escreva-as nos espaços. A resposta correta você encontrarí imediatamente abairo, ainda dentro do próprio quadro.

29 - E indispensável escrever a palavra (s) antes de olhar a resposta correta. Para tanto há necessidade de um pe daco de cartolina (ou similar) para cobrir a resposta enquanto você está procedendo a leitura do quadro.

39 - Não tente adivinhar. Cometerá poucos êrros se ler com atenção. Uma vez confirmada sua resposta passe ao qua dro seguinte.

MEDIDA DE TEMPERATURA

O grau de calor de qualquer cousa é denominado temperatura. Exemplo: o grau de calor de um quarto é a temperatura do querto.

Quando você toma a temperatura de um quarto, você está mẹ dindo a quantidade de de um quarto.

calor

A temperatura do corpo é o grau de calor do corpo.

Se você mede o grau de calor do corpo você está medindo a do corpo.

Temperatura

O corpo perde calor através da pele, dos pulmōes e da elimina çöes.

Qualquer cousa que afete a pele, os pulmōes ou as eliminaçōes pode contribuir para que o corpo perca 
calor

Quando se produz e se perde calor em conaiçōes de equilíbrio, se diz que a temperatura é normal.

Quando a quantidade de calor produzida é calor produzida é com pensada pela quantidade de calor perdido, a temperatura é

normal

O aumento da temṕeratura do corpo acima do normal indica tem peratura elevada.

Quando a temperatura ultrapassa a normal se diz

temperatura elevada

Quando a temperatura esté mais alta que a normal, se usa a pa lavra febre.

Um paciente com temperatura alta tem

febre

A causa mais comum da febre é a infeccāo. A luta do corpo contra a Infeç̧̃o pode produzir febre.

$O$ paciente com febre possivelmente tem

infeç̧̄o 
A inquitetação e a sêde podem ser sinals de uma temperatura elevadia ou febre.

O paciente que está intranquillo e que se queira de sede possivel mente tem

febre

Devido a febre o paciente perde líquido do corpo e isto lhe pro duz sềde.

O paciente com febre provivelmente the diria que tem

$$
\text { sêde }
$$

Frequentemente, a pele quente e ressecada significa que o pa ciente tem febre.

A pele _ possívelmente significa que o paciente tem febre.

quente e ressecada

\section{REFERENCIAS BIBLIOGRAFICAS}

ALVIM, E. de F. - Instruçāo programada. Revista Bragileire de Enfermagem, 19 (4) : 343-350, agô., 1966.

CARvalHO, A.C. de - Método de auto-ingtrução: instrução programada. Revista Bragileire de Enfermagem, 19 (4) : 332-342, agô., 1966.

EVANS, J.L. - Princípios de aprendizagem programada. (fo lheto mimeografado).

GOODSON, C.L. - Medición de la temperatura, del pulso y de la respiración. Bethesda,Secretarin de Salud, Educación 
y Bienestar, 1966.

ORGANIZAÇĀO MUNDIAL DA SAđDE - Informe del seminário sobre adiestramiento de auxiliares de enfermería: Mel gar, Colombia, 6-16 de deciembre de 1964. Washingtom, Organización Panamericana de la Salud, 1965. (In forme sobre Eenfermerin, 4).

ORGANIZAÇÃO MUNDIAL DE SAUDE - Postiles sobre o curso de instruçāo programada. México, Cuernavaca,out.1966.

BARBATO, M. G. - Instruçāo progra mada. Revista da Escola de Enfer magem da USP, $2(1): 28-38$, mar. $196 \overline{8}$ 